\title{
Root-originating dentinal defects: methodological aspects and clinical relevance
}

\author{
Peter Zahi Tawil ${ }^{1 *}$, Elisa Kristin Arnarsdottir ${ }^{1}$ and Marcelo Santos Coelho ${ }^{2}$
}

\begin{abstract}
It was in the 1980s when the association between root-filling procedures and dentinal microcracks was made. Nowadays, root-originating microcracks, also known as dentinal defects, are recognized as a possible precursor that is part of the longitudinal process of root-originating fractures. The presence of dentinal defects has been shown to significantly decrease the outcome through a periapical microsurgery model. Several in vitro articles have been published in the past years in regards to dentinal defects, but most of them have serious methodology concerns that will be discussed in this review.

A total grasp of the development and the role dentinal defects play in endodontics is crucial to the specialty. This review aims to discuss dentinal defects and their causative factors and the research models that have been used and their clinical significance. Through a comprehensive critical review of the literature, this article will express the need for further in vivo clinical research and better ex vivo methods that can replicate the clinical setting to answer several remaining questions about the development of and the role dentinal defects play in endodontics.
\end{abstract}

Keywords: Dentinal defects, Vertical root fracture, Root-originating fractures, Root-sectioning method, Transillumination, Micro-CT

\section{Introduction}

The American Association of Endodontists (AAE) classifies the longitudinal tooth fractures as five different types: craze lines, cuspal fractures, cracked tooth, split tooth, and vertical root fracture (American Association of Endodontists 2008). Vertical root fracture (VRF), also known as root-originating fracture (ROF), is the most catastrophic event among these presented; currently, no proposed treatment is efficient and root removal is the only predictable treatment modality. These ROFs have a peculiar aspect: while the outcome is known, the precise origin of this event is still unclear. Some theories can be made such as age of patient, excessive dentin removal, and parafunctional occlusion forces, but the certainty of its origin is yet to be found.

\footnotetext{
* Correspondence: pztawil@gmail.com

${ }^{1}$ Department of Endodontics, UNC School of Dentistry, University of North Carolina at Chapel Hill, 1150 First Dental Building, CB \#7450, Chapel Hill, NC 27599-7450, USA

Full list of author information is available at the end of the article
}

It was in the 1980s when Pitts et al. and Holcomb et al. described the possible association among root-filling procedures and dentinal microcracks or ROFs (Holcomb et al. 1987; Pitts et al. 1983). An interesting finding of theirs was that in some samples, the fracture did not fully spread from the canal to the root surface. It seemed to be a longitudinal process with a progressive aspect (Fig. 1). In the late 1990s, microcracks became a hot topic in relation to various canal preparation and obturation methods. Wilcox et al. were the first to report the presence of dentinal defects in the endodontic literature (Wilcox et al. 1997). They assessed the effects of lateral condensation forces after root canal enlargement in the development of ROFs. That study showed that stress generated inside a root canal space propagates through the dentin and develops into a fracture. One important conclusion of that study influenced research design over the years: only roots with previous dentinal defects developed a root fracture. These findings were supported with studies by Bier et al. and Shemesh et al. who found that root canal instrumentation and filling created 


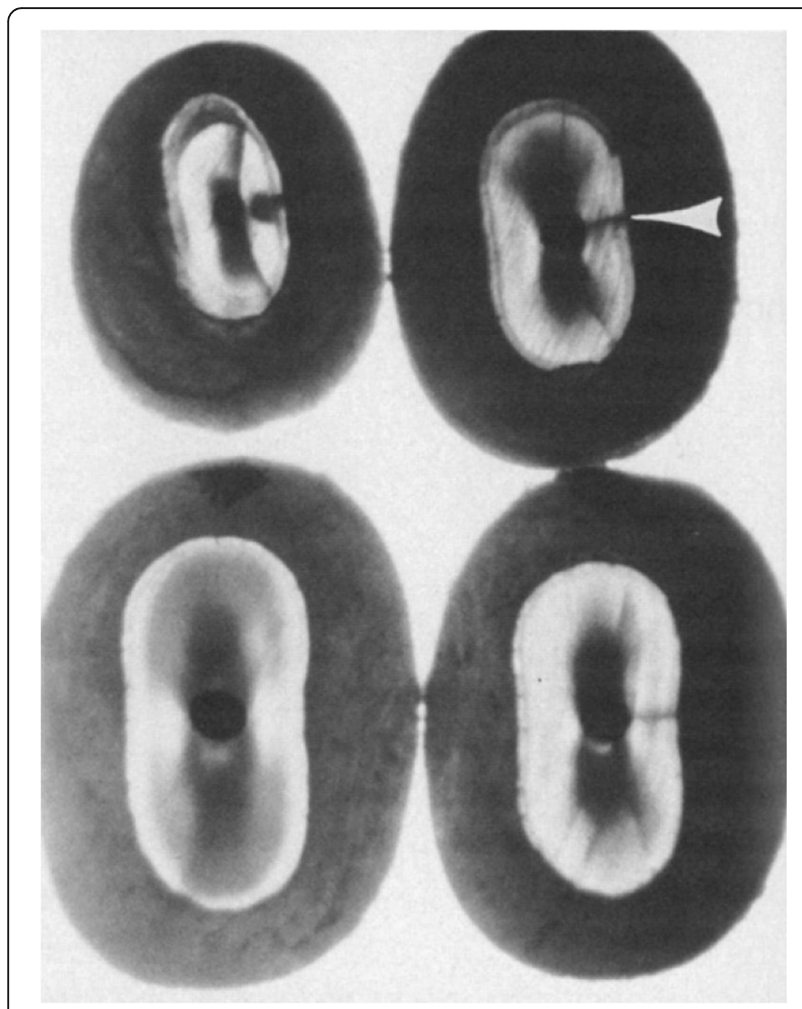

Fig. 1 Further investigation of spreader loads required to cause vertical root fracture during lateral condensation. Reproduced from Holcomb et al. (1987). J Endod, 13(6), 277-284 dentinal defects, incomplete cracks, and fractures (Bier et al. 2009; Shemesh et al. 2009). Shortly after that, dentinal defects became recognized as a possible precursor of the longitudinal process of ROFs. Subsequently, several studies attempted to assess endodontic procedures and their influence in dentinal defect creation.

Through an innovative light-emitting diode (LED) transillumination study design, the clinical significance of dentinal defects (Fig. 2) was established when it was correlated to a significant decrease in outcomes through a periapical microsurgery model (Tawil et al. 2015). However, the exact origin of such defects is still difficult to define. Several different methodologies have been used in an attempt to reproduce in vitro the visualization of dentinal defects after endodontic procedures such as thermography, scanning electronic microscopy, finite elements, root sectioning, and micro-CT scan (Ashwinkumar et al. 2014; Kim et al. 2010; Matsushita-Tokugawa et al. 2013; Saber and Schafer 2016; Zuolo et al. 2017).

Recently, some studies have questioned the findings of in vitro root-sectioning methodology studies. The rootsectioning method was modified through masking the un-instrumented roots to remove evaluator bias (Arias et al. 2014), using LED transillumination (Fig. 3) to improve specificity (Coelho et al. 2017), and recently, micro-CT technology has also been used (Zuolo et al. 2017). Micro-CT has the advantage of being a nondestructive method that allows the previous visualization

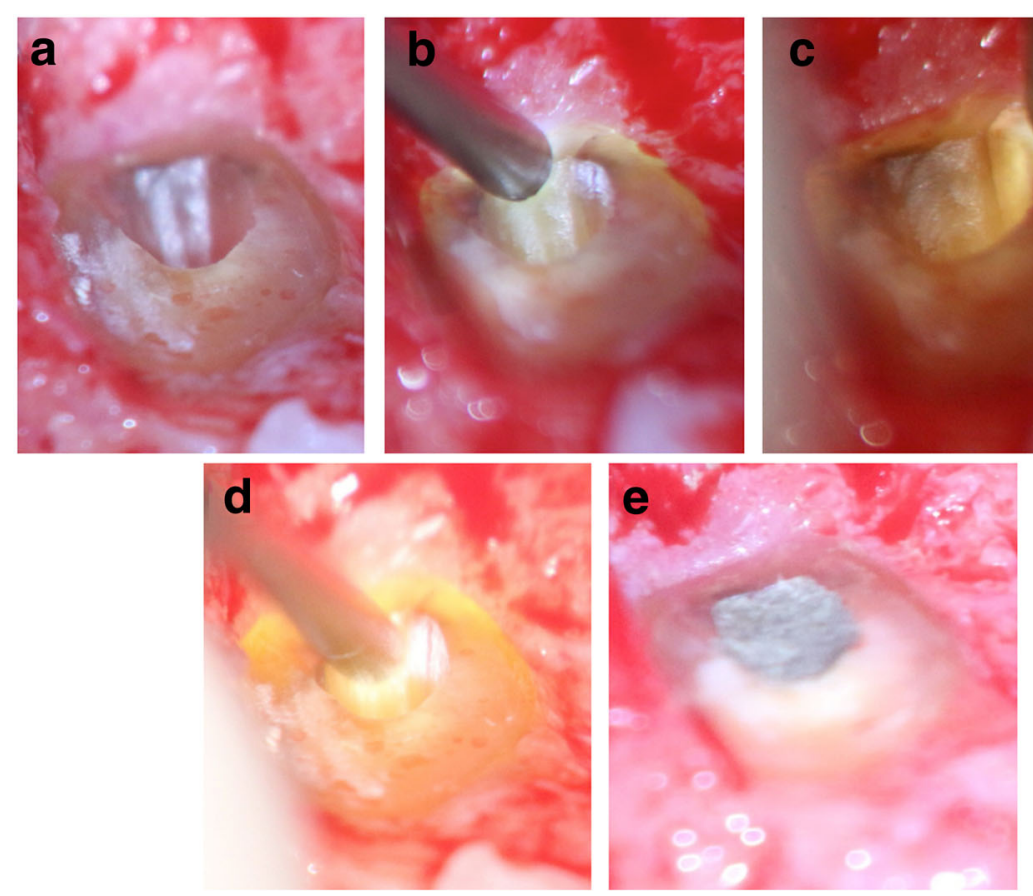

Fig. 2 Periapical microsurgery: the effect of root dentinal defects on short- and long-term outcome. Reproduced from Tawil et al. (2015). J Endod, $41(1), 22-27$ 


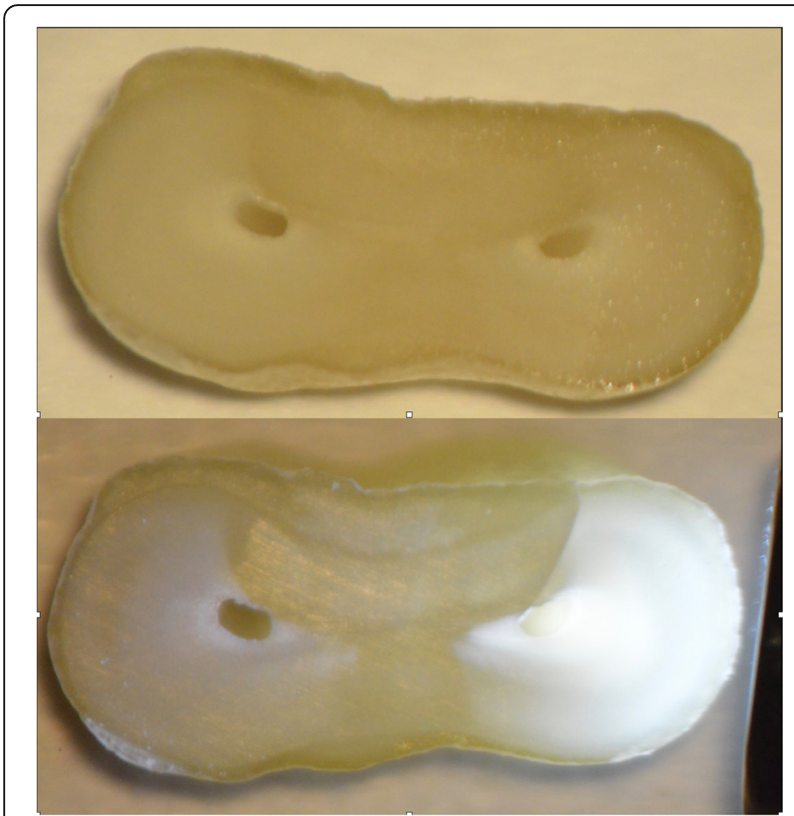

Fig. 3 Image showing a full thickness dentinal defect revealed through LED transillumination

of the roots without necessitating the use of a saw that might introduce defects unrelated to any tested endodontic procedure. However, it has been questioned if the scanning resolution offers enough sensitivity (Shemesh 2015) as dentinal defects do not have distinct physical separations in the dentin. The presence of physical separation is needed for digital signal processing which is why the term microcrack is often used in micro-CT studies (De-Deus et al. 2014; Ceyhanli et al. 2016). Furthermore, micro-CT is not a modality that can be used in a clinical study. No matter how accurate the resolution of a digital scanner is, there is still the limitation of ex vivo research. Studies also showed that the storage time, the hydration status of the specimen, and the extraction forces of teeth used in ex vivo models should be better controlled for meaningful results (Coelho et al. 2017; Lim et al. 2016). This review aims to discuss dentinal defects, their causative factors, their research models, and their clinical relevance.

\section{Review}

Different terminologies have been used to define dentinal defects such as cracks, microcracks, and fractures; some studies have also used "craze lines" to denominate defects in dentin, while the AAE classifies a craze line as an event located in the enamel. Shemesh et al. defined dentinal defects as all lines that appeared to disrupt the integrity of the dentin on the root end surface that extended either from the external root surface onto the resected dentin surface or from within the root canal lumen onto the resected root surface (Shemesh et al.
2009). It is our opinion that the term "dentinal defect" is the best available to describe this root-originating event.

\section{Etiology}

Through the past 20 years, there has been much speculation of the causative factors of dentinal defects. Among those factors are rotary NiTi instrumentation (Hin et al. 2013), taper of the instrumentation files (Bier et al. 2009), obturation (Shemesh et al. 2009; Shemesh et al. 2010), retreatment (Shemesh et al. 2011; Topcuoglu et al. 2014), post placement (Gluskin et al. 1995), crosssectional shape of the roots (Gutmann 1992), high concentration of sodium hypochlorite (Shemesh 2015), age changes (PradeepKumar et al. 2017), and parafunctional stresses (Cameron 1964). In this review, we will focus on the effects of instrumentation, obturation, and retreatments.

\section{Rotary NiTi instrumentation}

There are conflicting results in the literature regarding if $\mathrm{NiTi}$ rotary instruments cause dentinal defects. These conflicting results are likely due to issues from the methodology that was used and which will be discussed in further detail in the methodology section later in this review. Results of root-sectioning studies have presented dentinal defect creation rates of 28.3 to $50 \%$ after root canal instrumentation with ProTaper system (Burklein et al. 2013; Liu et al. 2013). Single-file reciprocating systems had a more drastic range of 5 to $80 \%$ (Abou El Nasr and Abd El Kader 2014; Burklein et al. 2013; Gergi et al. 2015; Liu et al. 2013; Saber and Schafer 2016).

It also has been speculated that an increase in taper could be a causative factor in defect creation (Bier et al. 2009). Bier's speculation was confirmed by Arlsan et al. and Liu et al., who found files with larger taper to create more dentinal defects in the root canal wall (Arslan et al. 2014; Liu et al. 2013). Increased taper removes more dentin and may increase the stress on the root canal wall, increasing the risk of a root fracture (Sathorn et al. 2005; Wilcox et al. 1997). However, a recent micro-CT study found no increase in dentinal defects after instrumentation, even when files with various taper were used (de Oliveira et al. 2017). We can once again see the conflicting results that can likely be due to the limitations of methodologies that were used.

Recent studies assessing defects after root canal instrumentation using root-sectioning methodology have presented different results from those obtained previously. Pedullà et al. assessed six different root canal instrumentation systems and have shown a small correlation between root canal instrumentation and dentinal defect creation (Pedulla et al. 2017). Coelho et al. assessed rotary and reciprocating systems; no difference among the experimental groups and the negative control group was 
found; therefore, it was concluded that there is no correlation between root canal instrumentation and dentinal defect creation (Coelho et al. 2016a).

Some other studies assessed instrumentation length and foramina management. Adorno et al. showed that instrumentation beyond the apex promoted more cracks than instrumentation within it (Adorno et al. 2011). On the other hand, Rose and Svec found no correlation between root canal instrumentation $1 \mathrm{~mm}$ beyond the apex with rotary, reciprocating, or hand instrumentation (Rose and Svec 2015). The differences in methodologies were paramount in leading to such different results. While the first study used extracted human teeth in dry conditions, the latter maintained the specimens in their environment-pig jaws of young animals. Recently, de Oliveira et al. found no defects after foramina enlargements in extracted human teeth using micro-CT analysis (de Oliveira et al. 2017), corroborating the findings of Rose and Svec.

Conversely, three studies using micro-CT methodology have presented microcracks after root canal instrumentation. Jamleh et al. eliminated the specimens that presented cracks before instrumentation and detected 90\% of specimens instrumented with ProTaper presenting dentinal defects after root canal instrumentation and $50 \%$ of the specimens instrumented with WaveOne (Jamleh et al. 2015). Similar results were achieved by Ceyhanli et al. that also found dentinal defects using micro-CT methodology (Ceyhanli et al. 2016). According to that study, $42 \%$ of specimens instrumented with ProTaper presented dentinal defects, along with $35 \%$ for Safesider and 25\% for Race system. Bayram et al. found new defects to be created after instrumentation with ProTaper Universal rotary system but not with ProTaper Gold, Self-Adjusting File, or XP-endo Shaper. They advocated that heat-treated file systems might not cause as many defects as traditional NiTi file systems (Bayram et al. 2017).

\section{Root canal obturation}

Various methods have been used to obturate root canals, but cold lateral and warm vertical condensation are the most common ones used today (Cailleteau and Mullaney 1997). Using a spreader to make space for accessory cones in lateral condensation can induce dentinal damage (Holcomb et al. 1987; Pitts et al. 1983; Wilcox et al. 1997). The main concern with the compaction of the filling material is the formation of tensile stress on the canal walls (Blum et al. 1998a, 1998b) exceeding the structural limit of the dentin and causing a defect. However, there are many variables to be considered in relation to lateral compaction in the development of dentinal defects or cracks, including the age of the patient, anatomy of the tooth, size of the preparation, dentinal thickness, spreader type, and load. A study by Shemesh et al. compared the prevalence of dentinal defects after lateral compaction and warm vertical condensation and found that both of them can create dentinal defects (Shemesh et al. 2010). His findings are consistent with Blum et al., who found that warm vertical compaction produces hydraulic forces, putting pressure on the canal walls that creates a wedging effect on the dentin (Blum et al. 1998a, 1998b). Although both techniques seem to create potential forces that could have an effect on dentinal defect creation, we still need better ex vivo methods to assess this factor, as well as higher level clinical evidence.

\section{Retreatment}

Retreatment is done after the initial root canal has failed. To access the complexity of a root canal system, the ideal goal it is to remove all of the previous obturation. To achieve the biological goal of disinfecting the canal system, the removal of the previous obturation is critical; however, this can be a difficult task (Hammad et al. 2008; Hulsmann and Bluhm 2004; Schirrmeister et al. 2006). The filling material is removed with the help of various instruments. Clinicians use solvents to soften the filling material, followed by mechanical instrumentation through hand, Hedström, or rotary NiTi retreatment files. The presence of a filling material adds resistance that requires increased mechanical stress when compared to primary root canal treatment. One of the consequences shown in ex vivo studies is increased formation of dentinal defects in the canal walls for both $\mathrm{NiTi}$ rotary and hand instrument techniques (Shemesh et al. 2011; Topcuoglu et al. 2014). It also has been speculated that the increased formation of dentinal defects in retreated teeth can explain why the rate of healing after retreatment is lower than the rate of primary root canal treatment (Shemesh et al. 2011). That being said, one has to remember the fact that the above studies on retreatment are all in vitro studies. Although these studies all have similar results, the formation of dentinal defects after retreatment procedures has yet to be evaluated clinically.

\section{Methodological aspects}

As mentioned previously in this article, different methodologies have been used in an attempt to assess dentinal defects through ex vivo models. These methods are thermography, scanning electronic microscopy, finite elements, optical coherence tomography, root sectioning, and micro-CT scan (Ashwinkumar et al. 2014; Kim et al. 2010; Matsushita-Tokugawa et al. 2013; Saber and Schafer 2016; Zuolo et al. 2017).

Root-sectioning techniques have been applied for many years to assess the influence of root canal 
instrumentation (Bier et al. 2009), root canal obturation (Shemesh et al. 2009; Shemesh et al. 2010), and retreatment (Ustun et al. 2015) on dentinal defect creation. This methodology relies on an un-instrumented group that serves as a control, compared to the experimental groups that have been submitted to different endodontic procedures. Roots are sectioned with a low-speed saw under water irrigation at different distances from the apex; pictures are taken under magnification and then evaluators can assess the presence/absence of dentinal defects. In spite of it being commonly used, this methodology has been criticized for poor sensitivity and specificity. It is sometimes hard to have proper control through ex vivo models as extraction forces and/or the diamond low-speed saw could either create or propagate dentinal defect (Coelho et al. 2017).

Some recent studies with slight changes in methods have presented dentinal defects in un-instrumented specimens (Coelho et al. 2016a, b). When Arslan et al. stained similar specimens, the percentage of dentinal defects observed was 16.6\% (Arslan et al. 2014). A different approach was adopted by Arias et al.: the root canal space was covered in order to mask for the evaluators whether the canals had been instrumented or not; in that study, when the evaluators were blinded, $50 \%$ of the un-instrumented specimens showed dentinal defects (Arias et al. 2014). Another recent study has focused only on un-instrumented roots; the canal space of the specimens was masked, and the evaluators observed 10\% of mandibular molars with dentinal defects (Coelho et al. 2016b). Moreover, this study used light-emitting diode (LED) transillumination resulting in an increase in dentinal defect detection in the same specimens, up to $47.5 \%$ (Fig. 4). This issue was also assessed through a

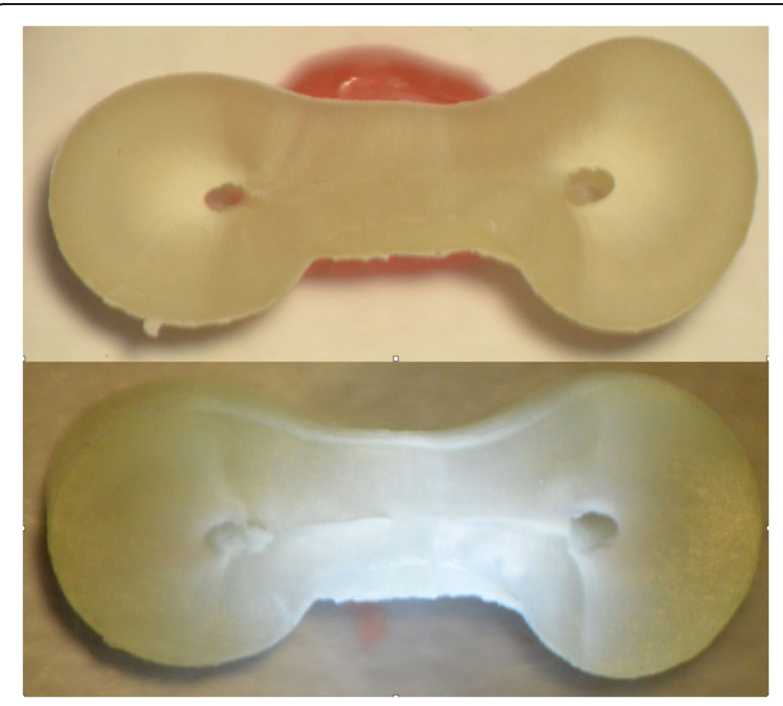

Fig. 4 Image showing partial thickness dentinal defects revealed through LED transillumination
micro-CT model that found a rate of $7.1 \%$ of dentinal defects in 633 extracted teeth with un-instrumented roots (PradeepKumar et al. 2017). All the defects noted in that study were in the mesiodistal direction and more common in mandibular teeth of older people (40 years and older). The results of these studies demonstrated that dentinal defects can already be present in uninstrumented roots that are often used as negative controls in several older, published articles.

Another factor to consider in ex vivo models is the storage conditions of the teeth. It was recently shown that storage conditions play a role in the presence of dentinal defects (Coelho et al. 2017). This was shown by assessing fresh, periodontally compromised teeth that were extracted atraumatically. The fresh roots with minimal extraction forces presented $16.6 \%$ of dentinal defects, while teeth with no control of such conditions presented $71 \%$ of specimens with defects. Lim et al. obtained similar results using a micro-CT methodology; specimens in dry conditions presented dentinal defects after root canal instrumentation, while specimens kept in humid conditions had no defects after the same procedures (Lim et al. 2016).

With the development of micro-CT scanning, dentinal defects could be potentially assessed without sectioning the roots. This can help, as the same sample can serve as its own control. Studies that have used micro-CT pointed out that dentinal defects are present in uninstrumented roots (Ceyhanli et al. 2016; De-Deus et al. 2014; Jamleh et al. 2015), which is in agreement with recent studies with the root-sectioning methodology. However, as stated earlier, it has been questioned if the scanning resolution offers enough sensitivity (Shemesh 2015) as dentinal defects do not have distinct physical separations in the dentin. The presence of physical separation is needed for digital signal processing which is why the term microcrack is often used in micro-CT studies (De-Deus et al. 2014; Ceyhanli et al. 2016). In the science of digital signal processing, the NyquistShannon sampling theorem states that to digitally detect an entity, the signal has to be at least two times larger than the voxel size. This means that the size of the defect needs to be twice as wide as the voxel size. Therefore, a definite physical separation has to be present to be detected through digital signal processing technology. That could explain why a higher percentage of defects was detected in studies when an LED transillumination and magnification was used.

One has to understand that both micro-CT and rootsectioning methodologies have pros and cons. It is clear that the root-sectioning methodology has overestimated the presence of dentinal defects due to the physical need to section the roots to be analyzed. On the other hand, one may question whether the micro-CT methodology 
is in reality underestimating its presence. Micro-CT is limited by its resolution, and since there is no physical separation of the dentin, it might be impossible to detect such fine defects. The different results in micro-CT studies can be due to the different scanning resolutions of the units that were used, the number of crosssectional images that were assessed, inter/intra observer reliability, and the presence of digital artifacts.

Old root-sectioning studies have been criticized for a lack of proper controls due to poor sensitivity (Coelho et al. 2017). With a lack of proper sensitivity, the control groups of old sectioning studies are flawed and their results should be interpreted with caution. The addition of LED transillumination has improved the sensitivity of the sectioning methodology and should always be considered. With improved sensitivity, both the sectioning methodology and micro-CT models have shown dentinal defects in un-instrumented specimens (Coelho et al. 2016b; PradeepKumar et al. 2017). Having proper sensitivity is crucial for proper controls in future studies. These conflicting results also highlight the limitation of in vitro research and the importance of having a proper in vivo clinical model for assessing this important issue.

\section{Clinical relevance}

While laboratory studies presented dentinal defects in up to $90 \%$ of the specimens, clinical studies of endodontically treated teeth suggest the prevalence of ROF ranges from 3.69 to 20\% (PradeepKumar et al. 2016). This implies that either there is overestimation of dentinal defects due to the methodological limitations of in vitro studies or not all of the defects propagate into ROFs. A retrospective clinical study showed root fracture to be responsible for $36 \%$ of the reasons for extraction after a 10-year follow-up (Landys Boren et al. 2015). That study showed that $80 \%$ of the teeth survived for 10 years; proper restoration and age were important predictors of survival rate.

Aging has been pointed out as an important factor for ROF development by PradeepKumar et al. as the majority of fractures clinically occurred in patients older than 40 years (PradeepKumar et al. 2016). Some in vitro studies corroborated the influence of aging in the presence of dentinal defects in un-instrumented roots as dentinal defects were present in $16.6 \%$ of roots from patients with mean age of 54 years old and $50 \%$ in 81 -year old patients (Arias et al. 2014; Coelho et al. 2017). A recent micro-CT study showed significantly more dentinal defects in roots obtained from patients ranging from 40 to 71 years when compared to patients with an age range of 20-39 years old (PradeepKumar et al. 2017). These results are in agreement with the findings of Ivancik et al. that showed aging as a factor that reduces the resistance of coronal dentin (Ivancik et al. 2012).
In a review, Tsesis et al. presented the challenges of properly diagnosing vertical root fractures (Tsesis et al. 2010). They emphasized that while a quick diagnosis and management is necessary, there is still no data supporting clinical and radiographic evaluation methods. Even with the advent of cone beam computed tomography $(\mathrm{CBCT})$, we still do not have enough resolution to clinically diagnose the presence of an ROF in a predictable fashion. A CBCT-dedicated review has shown the limitations of this technology in the detection of ROF, concluding that CBCT on its own is not enough for proper predictable diagnosis of ROF (Patel et al. 2015). It seems reasonable to conclude that although $\mathrm{CBCT}$ can be helpful, the direct visualization of the defects and/or fracture is still the most predictable.

Few studies have been dedicated to clinically evaluate the in vivo presence of dentinal defects (Fig. 5). Song et al. noted it as a cause of failure in a periapical microsurgical study (Song et al. 2011). An interesting aspect of that study is that cracks were present in only $1 \%$ of the failed cases assessed under the

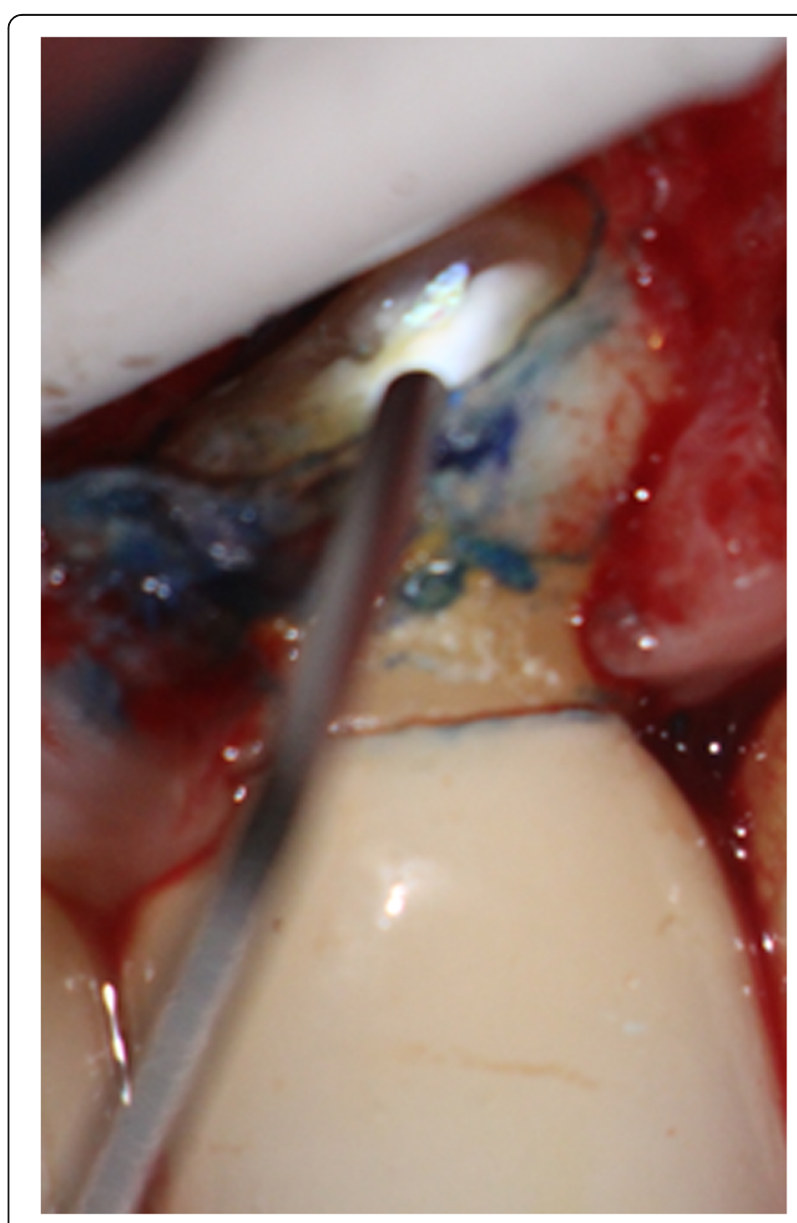

Fig. 5 Image showing a clinical partial thickness dentinal defect revealed through LED transillumination 
operating microscope. These findings suggest that in vitro studies might have overestimated the presence of dentinal defects as the percentage of ROF seems to be low. A recent study, however, found a higher incidence of dentinal defects in periapical microsurgery. Tawil et al. evaluated the outcomes of periapical microsurgery after 1- and 3-year intervals (Tawil et al. 2015). The presence of dentinal defects was assessed with the aid of a $0.8-\mathrm{mm}$ LED transilluminator. The 3-year follow-up showed complete radiographic bone healing of $31.5 \%$ when dentinal defects were present and $97.3 \%$ when absent. The authors concluded that dentinal defects have a significant influence on the outcomes of periapical microsurgery.

In another study, Tawil assessed whether ultrasonic root-end preparation in periapical microsurgery could either create or propagate dentinal defects (Tawil 2016). Eighty-one roots were assessed under LED transillumination before and after root-end preparation. The defects were classified as none, partial, or full. Fifty-one roots were intact and remained intact after ultrasonic preparation, while 14 out of 26 of the partial defects propagated into a full dentinal defect. This showed that ultrasonic root-end preparation is safe for intact roots; however, it can propagate pre-existing dentinal defects.

We still need further clinical research or better in vitro methods that can replicate the clinical setting to answer several remaining questions about the development of and the role of dentinal defects in endodontics.

\section{Conclusions}

Several in vitro studies showed a high incidence of dentinal defects after endodontic procedures, but some recent studies have highlighted concerns with the older study designs. The presence of dentinal defects has been associated with failures in periapical microsurgery and is likely part of the longitudinal progression of ROF. Complete comprehension about the development of and the role of dentinal defects in endodontics is a great challenge that needs to be addressed.

Several factors have been associated with ROF: age, parafunctional habits, overfilling, and poor restoration (Ivancik et al. 2012; PradeepKumar et al. 2016; Qiao et al. 2017). Recently, the change in bite forces after root canal treatment has been shown and should be investigated further as a potential factor (Awawdeh et al. 2017). It is important to understand the role of pulp and periodontal cells as a protective sensor in fracture prevention. We still need further clinical research or better methods that can replicate the clinical setting to answer several remaining questions about the development of and the role of dentinal defects in endodontics.

\section{Abbreviations}

AAE: American Association of Endodontists; CBCT: Cone beam computed tomography; LED: Light-emitting diode; ROF: Root-originating fracture; VRF: Vertical root fracture

\section{Acknowledgements}

The authors would like to acknowledge the professional support of Beth Rodgers, Editor, for her professional writing services.

\section{Funding}

Not applicable

\section{Availability of data and materials}

Data sharing is not applicable to this article as no datasets were generated or analyzed during the current study.

\section{Authors' contributions}

PZT conceived the review paper and its design, coordination, documentation and figures; reviewed the quoted articles; and helped to draft the manuscript as a whole. EKA did the comprehensive in-depth literature review, wrote part of the manuscript, and contributed in the editing of the manuscript. MSC worked on reviewing the literature review and its context in the manuscript, provided figures, wrote part of the manuscript, and contributed in the editing of the manuscript. All authors (PZT, MSC, EKA) read, reviewed, edited, and approved the final manuscript.

\section{Authors' information}

- Peter Zahi Tawil DMD, MS, FRCD(C), Dip ABE: Graduate Program Director at the University of North Carolina at Chapel Hill, Department of Endodontics. Chapel Hill, NC, USA.

- Elisa Kristin Arnarsdottir DDS: MS candidate and endodontic resident at the University of North Carolina at Chapel Hill, Department of Endodontics, Chapel Hill, NC, USA.

- Marcelo Santos Coelho DDS, MSc: PhD candidate at the Department of Endodontics, UNIP-Universidade Paulista, Sorocaba, São Paulo, Brazil

Ethics approval and consent to participate

Not applicable.

Consent for publication

Not applicable.

Competing interests

The authors declare that they have no competing interests.

\section{Publisher's Note}

Springer Nature remains neutral with regard to jurisdictional claims in published maps and institutional affiliations.

\section{Author details}

${ }^{1}$ Department of Endodontics, UNC School of Dentistry, University of North Carolina at Chapel Hill, 1150 First Dental Building, CB \#7450, Chapel Hill, NC 27599-7450, USA. ²Department of Endodontics, UNIP_-Universidade Paulista, Sorocaba, São Paulo, Brazil.

Received: 30 September 2017 Accepted: 7 December 2017

Published online: 21 December 2017

\section{References}

Abou El Nasr HM, Abd El Kader KG. Dentinal damage and fracture resistance of oval roots prepared with single-file systems using different kinematics. J Endod. 2014;40(6):849-51.

Adorno CG, Yoshioka T, Suda H. Crack initiation on the apical root surface caused by three different nickel-titanium rotary files at different working lengths. J Endod. 2011;37(4):522-5.

American Association of Endodontists. Cracking the cracked tooth code: detection and treatment of various longitudinal tooth fractures: Colleagues for Excellence. Chicago: American Association of Endodontists; 2008. https:// www.aae.org/specialty/newsletter/cracking-cracked-tooth-code/. 
Arias A, Lee YH, Peters Cl, Gluskin AH, Peters OA. Comparison of 2 canal preparation techniques in the induction of microcracks: a pilot study with cadaver mandibles. J Endod. 2014;40(7):982-5.

Arslan H, Karatas E, Capar ID, Ozsu D, Doganay E. Effect of ProTaper Universal, Endoflare, Revo-S, HyFlex coronal flaring instruments, and Gates Glidden drills on crack formation. J Endod. 2014;40(10):1681-3.

Ashwinkumar V, Krithikadatta J, Surendran S, Velmurugan N. Effect of reciprocating file motion on microcrack formation in root canals: an SEM study. Int Endod J. 2014;47(7):622-7.

Awawdeh L, Hemaidat K, Al-Omari W. Higher maximal occlusal bite force in endodontically treated teeth versus vital contralateral counterparts. J Endod. 2017:43(6):871-5.

Bayram HM, Bayram E, Ocak M, Uygun AD, Celik HH. Effect of ProTaper Gold, SelfAdjusting File, and XP-endo shaper instruments on dentinal microcrack formation: a micro-computed tomographic study. J Endod. 2017;43(7):1166-9.

Bier CA, Shemesh H, Tanomaru-Filho M, Wesselink PR, Wu MK. The ability of different nickel-titanium rotary instruments to induce dentinal damage during canal preparation. J Endod. 2009;35(2):236-8.

Blum JY, Machtou P, Micallef JP. Analysis of forces developed during obturations. Wedging effect: part I. J Endod. 1998a;24(4):217-22.

Blum JY, Machtou P, Micallef JP. Analysis of forces developed during obturations. Wedging effect: part II. J Endod. 1998b;24(4):223-8.

Burklein S, Tsotsis P, Schafer E. Incidence of dentinal defects after root canal preparation: reciprocating versus rotary instrumentation. J Endod. 2013;39(4): $501-4$.

Cailleteau JG, Mullaney TP. Prevalence of teaching apical patency and various instrumentation and obturation techniques in United States dental schools. J Endod. 1997;23(6):394-6.

Cameron CE. Cracked-tooth syndrome. J Am Dent Assoc. 1964;68:405-11.

Ceyhanli KT, Erdilek N, Tatar I, Celik D. Comparison of ProTaper, RaCe and Safesider instruments in the induction of dentinal microcracks: a micro-CT study. Int Endod J. 2016:49(7):684-9.

Coelho MS, Card SJ, Tawil PZ. Light-emitting diode assessment of dentinal defects after root canal preparation with Profile, TRUShape, and WaveOne Gold systems. J Endod. 2016a;42(9):1393-6.

Coelho MS, Card SJ, Tawil PZ. Visualization enhancement of dentinal defects by using light-emitting diode transillumination. J Endod. 2016b;42(7):1110-3.

Coelho MS, Card SJ, Tawil PZ. Light-emitting diode assessment of dentinal defects: the role of presumed extraction forces. Restor Dent Endod. 2017; 42(3):232-9.

De Oliveira BP, Camara AC, Duarte DA, Heck RJ, Antonino ACD, Aguiar CM. Micro-computed tomographic analysis of apical microcracks before and after root canal preparation by hand, rotary, and reciprocating instruments at different working lengths. J Endod. 2017;43(7):1143-7.

De-Deus G, Silva EJ, Marins J, Souza E, Neves Ade A, Belladonna G, Versiani MA. Lack of causal relationship between dentinal microcracks and root canal preparation with reciprocation systems. J Endod. 2014:40(9):1447-50.

Gergi RM, Osta NE, Naaman AS. Dentinal crack formation during root canal preparations by the twisted file adaptive, Reciproc and WaveOne instruments. Eur J Dent. 2015;9(4):508-12.

Gluskin AH, Radke RA, Frost SL, Watanabe LG. The mandibular incisor: rethinking guidelines for post and core design. J Endod. 1995;21(1):33-7.

Gutmann JL. The dentin-root complex: anatomic and biologic considerations in restoring endodontically treated teeth. J Prosthet Dent. 1992;67(4):458-67.

Hammad M, Qualtrough A, Silikas N. Three-dimensional evaluation of effectiveness of hand and rotary instrumentation for retreatment of canals filled with different materials. J Endod. 2008;34(11):1370-3.

Hin ES, Wu MK, Wesselink PR, Shemesh H. Effects of self-adjusting file, Mtwo, and ProTaper on the root canal wall. J Endod. 2013:39(2):262-4.

Holcomb JQ, Pitts DL, Nicholls Jl. Further investigation of spreader loads required to cause vertical root fracture during lateral condensation. J Endod. 1987; 13(6):277-84

Hulsmann M, Bluhm V. Efficacy, cleaning ability and safety of different rotary NiTi instruments in root canal retreatment. Int Endod J. 2004;37(7):468-76.

Ivancik J, Majd H, Bajaj D, Romberg E, Arola D. Contributions of aging to the fatigue crack growth resistance of human dentin. Acta Biomater. 2012:8(7): 2737-46

Jamleh A, Komabayashi T, Ebihara A, Nassar M, Watanabe S, Yoshioka T, Suda H. Root surface strain during canal shaping and its influence on apical microcrack development: a preliminary investigation. Int Endod J. 2015; 48(12):1103-11.
Kim HC, Lee MH, Yum J, Versluis A, Lee CJ, Kim BM. Potential relationship between design of nickel-titanium rotary instruments and vertical root fracture. J Endod. 2010;36(7):1195-9.

Landys Boren D, Jonasson P, Kvist T. Long-term survival of endodontically treated teeth at a public dental specialist clinic. J Endod. 2015;41(2):176-81.

Lim H, Li FC, Friedman S, Kishen A. Residual microstrain in root dentin after canal instrumentation measured with digital Moire interferometry. J Endod. 2016; 42(9):1397-402.

Liu R, Hou BX, Wesselink PR, Wu MK, Shemesh H. The incidence of root microcracks caused by 3 different single-file systems versus the ProTaper system. J Endod. 2013;39(8):1054-6.

Matsushita-Tokugawa M, Miura J, Iwami Y, Sakagami T, Izumi Y, Mori N, Ebisu S. Detection of dentinal microcracks using infrared thermography. J Endod. 2013;39(1):88-91

Patel S, Durack C, Abella F, Shemesh H, Roig M, Lemberg K. Cone beam computed tomography in endodontics-a review. Int Endod J. 2015;48(1):3-15.

Pedulla E, Genovesi F, Rapisarda S, La Rosa GR, Grande NM, Plotino G, Adorno CG. Effects of 6 single-file systems on dentinal crack formation. J Endod. 2017;43(3):456-61.

Pitts DL, Matheny HE, Nicholls Jl. An in vitro study of spreader loads required to cause vertical root fracture during lateral condensation. J Endod. 1983;9(12): 544-50.

PradeepKumar AR, Shemesh H, Chang JW, Bhowmik A, Sibi S, Gopikrishna V, Kishen A. Preexisting dentinal microcracks in nonendodontically treated teeth: an ex vivo micro-computed tomographic analysis. J Endod. 2017;43(6): 896-900.

PradeepKumar AR, Shemesh H, Jothilatha S, Vijayabharathi R, Jayalakshmi S, Kishen A. Diagnosis of vertical root fractures in restored endodontically treated teeth: a time-dependent retrospective cohort study. J Endod. 2016; 42(8):1175-80

Qiao F, Chen M, Hu X, Niu K, Zhang X, Li Y, Wu L. Cracked teeth and poor oral masticatory habits: a matched case-control study in China. J Endod. 2017; 43(6):885-9.

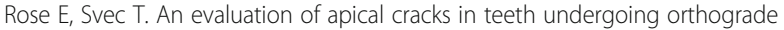
root canal instrumentation. J Endod. 2015;41(12):2021-4.

Saber SE, Schafer E. Incidence of dentinal defects after preparation of severely curved root canals using the Reciproc single-file system with and without prior creation of a glide path. Int Endod J. 2016;49(11):1057-64.

Sathorn C, Palamara JE, Messer HH. A comparison of the effects of two canal preparation techniques on root fracture susceptibility and fracture pattern. J Endod. 2005;31(4):283-7.

Schirrmeister JF, Wrbas KT, Meyer KM, Altenburger MJ, Hellwig E. Efficacy of different rotary instruments for gutta-percha removal in root canal retreatment. J Endod. 2006;32(5):469-72.

Shemesh $\mathrm{H}$. Endodontic instrumentation and root filling procedures: effect on mechanical integrity of dentin. Endod Top. 2015;33:43-9.

Shemesh H, Bier CA, Wu MK, Tanomaru-Filho M, Wesselink PR. The effects of canal preparation and filling on the incidence of dentinal defects. Int Endod J. 2009:42(3):208-13.

Shemesh H, Roeleveld AC, Wesselink PR, Wu MK. Damage to root dentin during retreatment procedures. J Endod. 2011;37(1):63-6.

Shemesh H, Wesselink PR, Wu MK. Incidence of dentinal defects after root canal filling procedures. Int Endod J. 2010;43(11):995-1000.

Song M, Kim HC, Lee W, Kim E. Analysis of the cause of failure in nonsurgical endodontic treatment by microscopic inspection during endodontic microsurgery. J Endod. 2011;37(11):1516-9.

Tawil PZ. Periapical microsurgery: can ultrasonic root-end preparations clinically create or propagate dentinal defects? J Endod. 2016;42(10):1472-5.

Tawil PZ, Saraiya VM, Galicia JC, Duggan DJ. Periapical microsurgery: the effect of root dentinal defects on short- and long-term outcome. J Endod. 2015:41(1):22-7.

Topcuoglu HS, Demirbuga S, Tuncay O, Pala K, Arslan H, Karatas E. The effects of Mtwo, R-Endo, and D-RaCe retreatment instruments on the incidence of dentinal defects during the removal of root canal filling material. J Endod. 2014;40(2):266-70.

Tsesis I, Rosen E, Tamse A, Taschieri S, Kfir A. Diagnosis of vertical root fractures in endodontically treated teeth based on clinical and radiographic indices: a systematic review. J Endod. 2010;36(9):1455-8.

Ustun Y, Topcuoglu HS, Duzgun S, Kesim B. The effect of reciprocation versus rotational movement on the incidence of root defects during retreatment procedures. Int Endod J. 2015:48(10):952-8. 
Wilcox LR, Roskelley C, Sutton T. The relationship of root canal enlargement to finger-spreader induced vertical root fracture. J Endod. 1997;23(8):533-4.

Zuolo ML, De-Deus G, Belladonna FG, Silva EJ, Lopes RT, Souza EM, Zaia AA. Micro-computed tomography assessment of dentinal micro-cracks after root canal preparation with TRUShape and self-adjusting file systems. J Endod. 2017:43(4):619-22.

\section{Submit your manuscript to a SpringerOpen ${ }^{\bullet}$ journal and benefit from:}

- Convenient online submission

- Rigorous peer review

- Open access: articles freely available online

- High visibility within the field

- Retaining the copyright to your article

Submit your next manuscript at $\boldsymbol{\sim}$ springeropen.com 